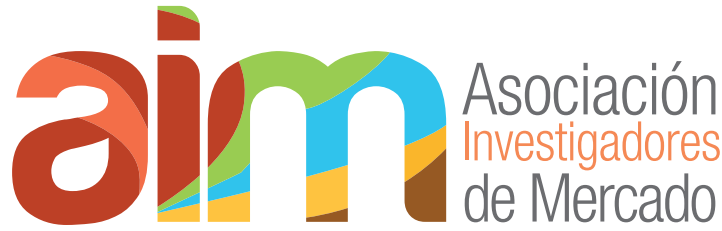 \\ Nueva metodología de segmentación y clasificación socioeconómica.
}

2018

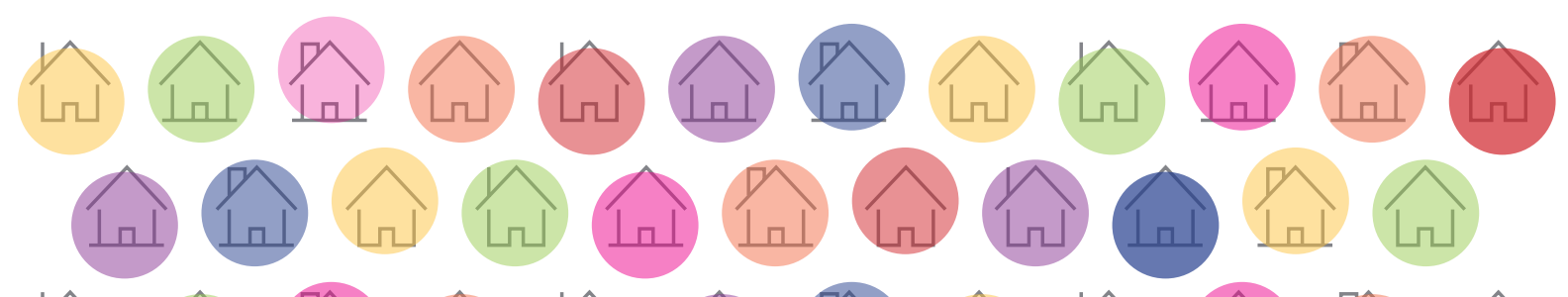

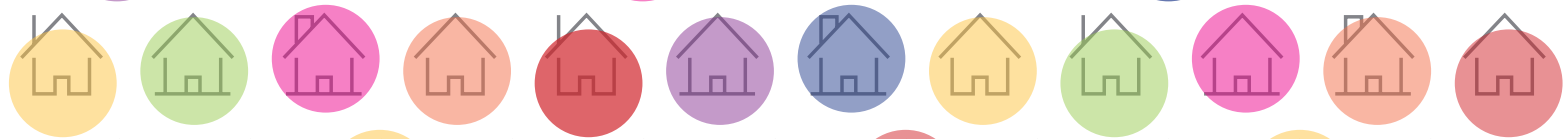

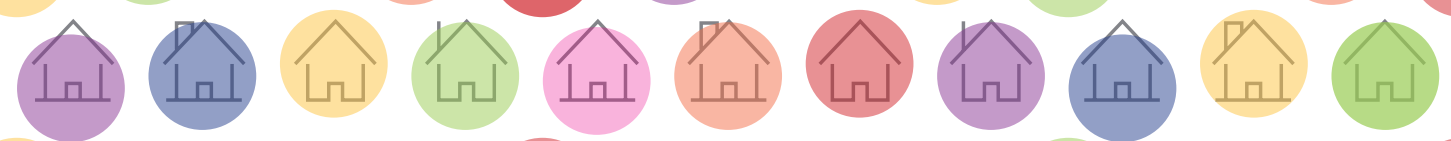

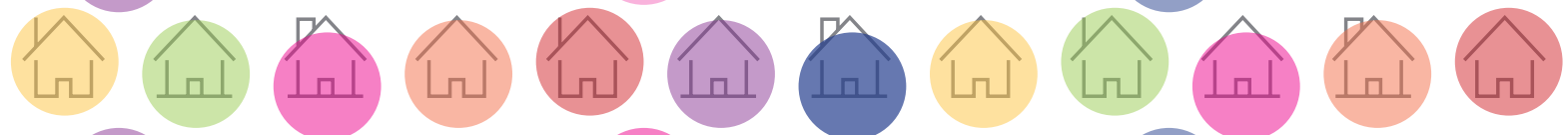

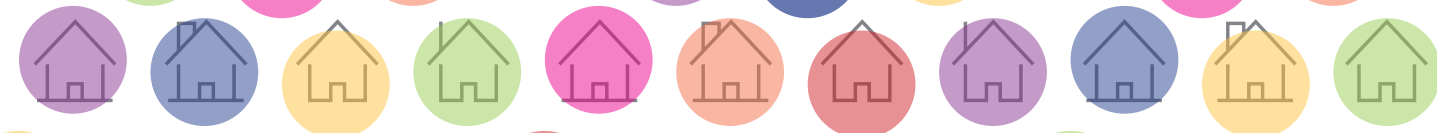

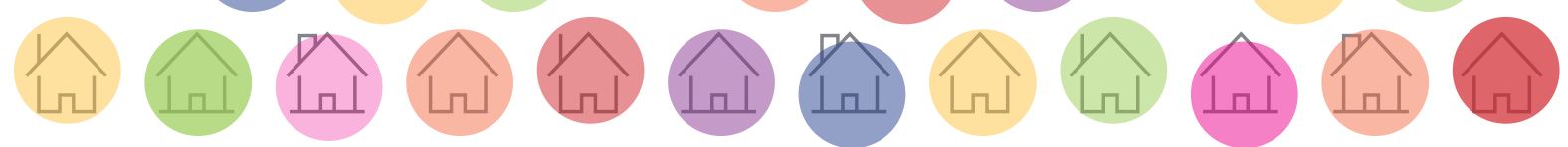

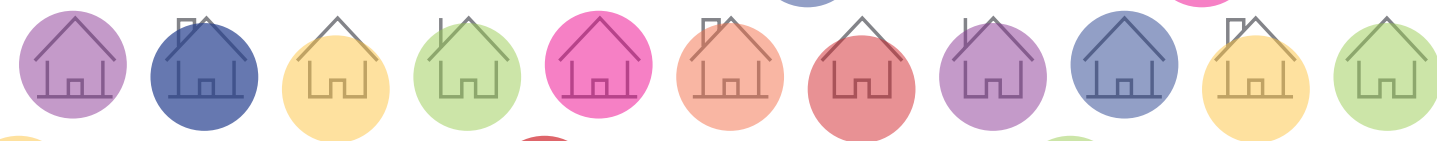

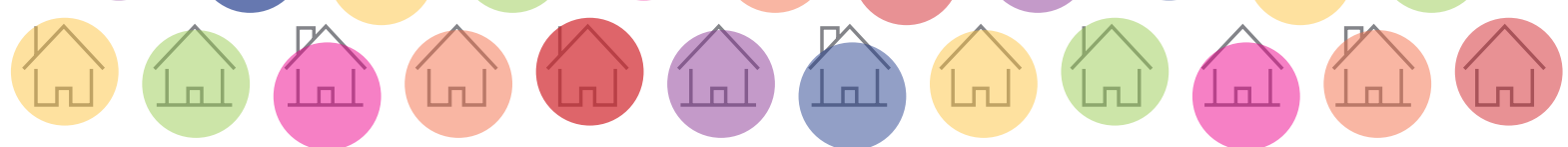

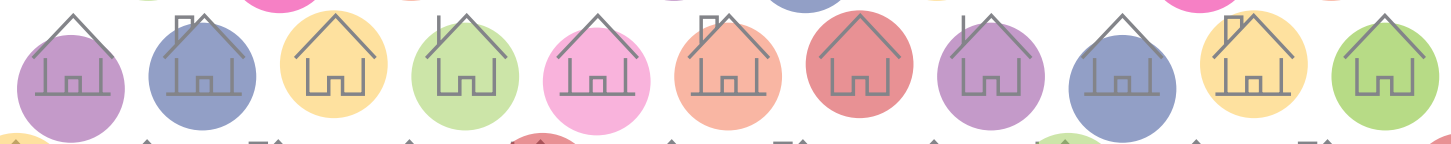

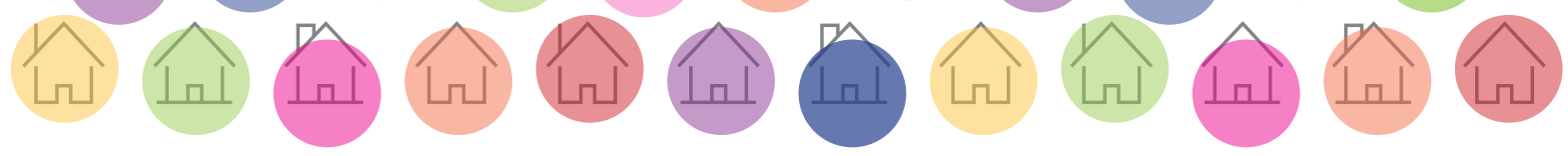




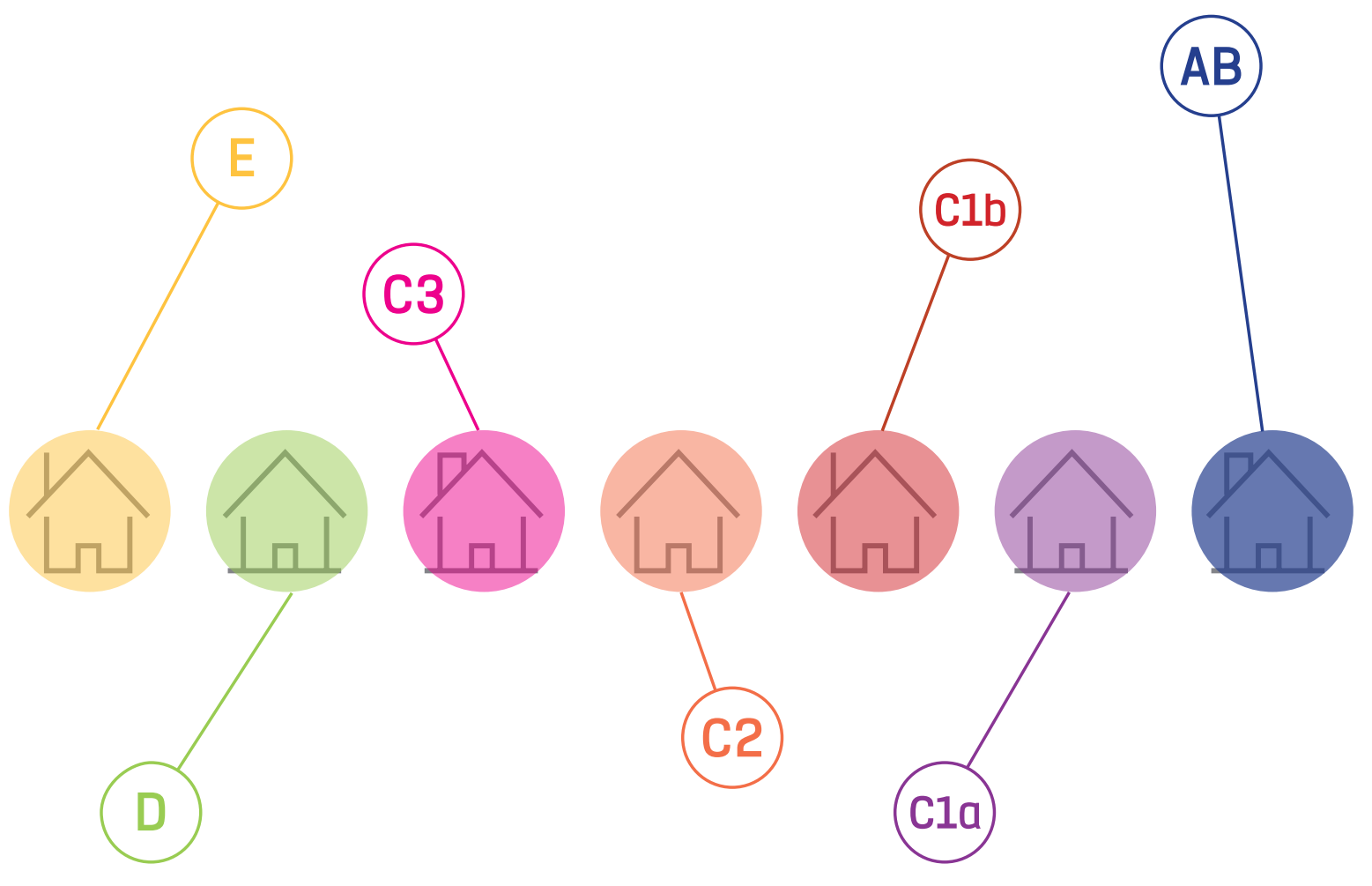

El índice socioeconómico es un puntaje que resume la información de 3 indicadores, el cual permite jerarquizar los hogares de Chile según su nivel de bienestar, y es la base para definir los grupos socioeconómicos (GSE). 


\section{Cómo clasificamos}

Calculamos un indice que estima el grado de bienestar relativo de un hogar y sus miembros, a partir de su tramo de ingreso (per cápita equivalente) y de los niveles educacional y ocupacional de su principal sostenedor. Partiendo del umbral que corresponde a la linea de pobreza definida por el INE, establecimos intervalos regulares del indice que delimitan a los demás grupos socioeconómicos. Con esto, definimos cortes que dividen a las personas en determinados grupos, a los cuales asignamos un nombre para identificarlos.

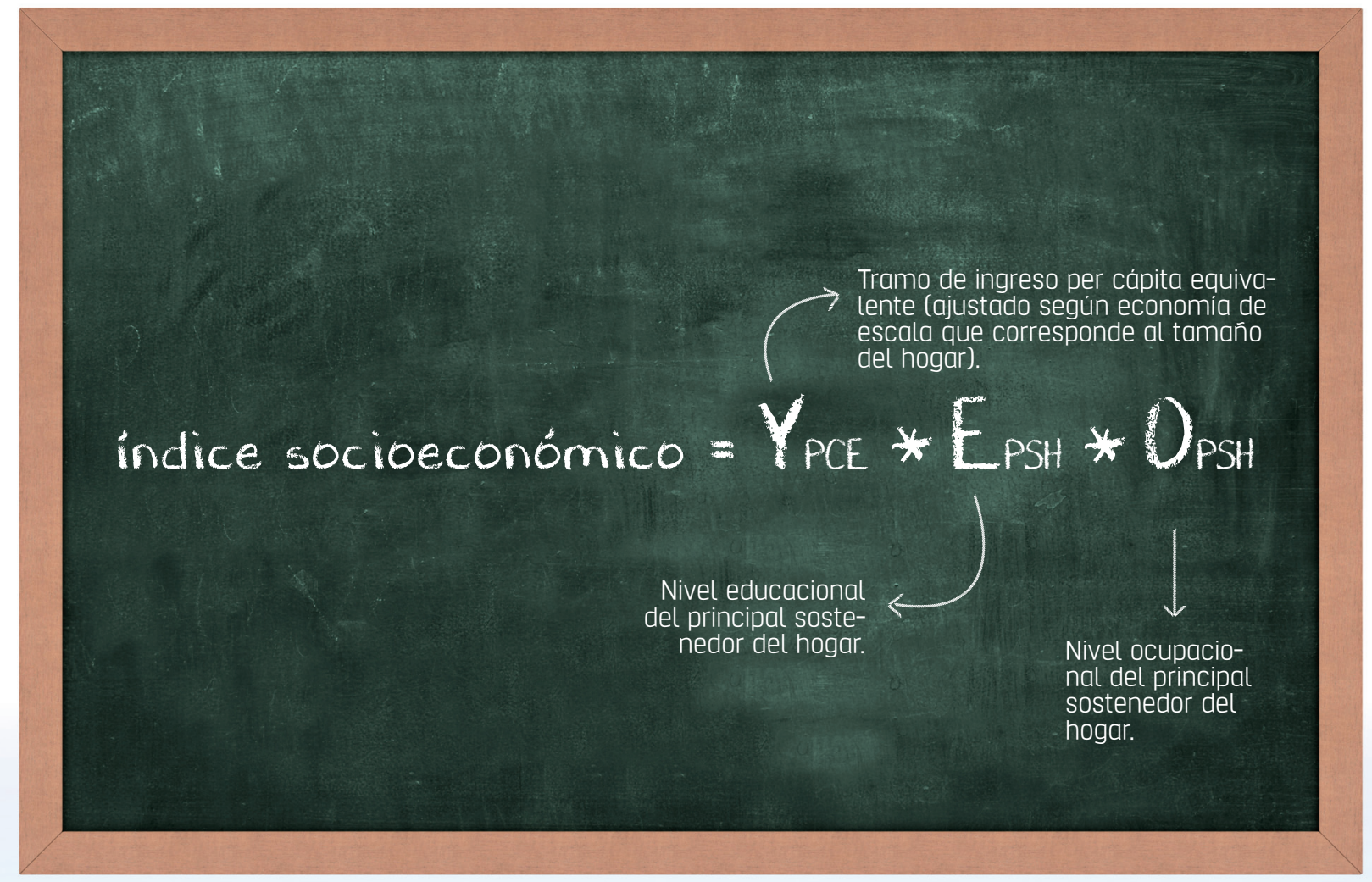




\section{Cuáles son \\ nuestras fuentes}

Por primera vez, la metodologia de clasificación se basa integramente en el análisis de estadisticas públicas que caracterizan en detalle los hogares chilenos y con muestras de gran tamaño.

- Encuesta de Presupuestos Familiares: Registra detalladamente los gastos de una muestra probabilistica de 10.528 hogares chilenos en 1.067 items agrupados en 12 categorias a lo largo de un año (de noviembre de 2011 a octubre de 2012). La usamos para describir a los distintos segmentos en términos de variables de consumo.

- Encuesta CASEN 2015: Caracteriza socioeconómicamente una muestra probabilistica de 83.887 hogares de Chile.

La usamos para proyectar el indice socioeconómico de todo el pais, con representatividad regional.

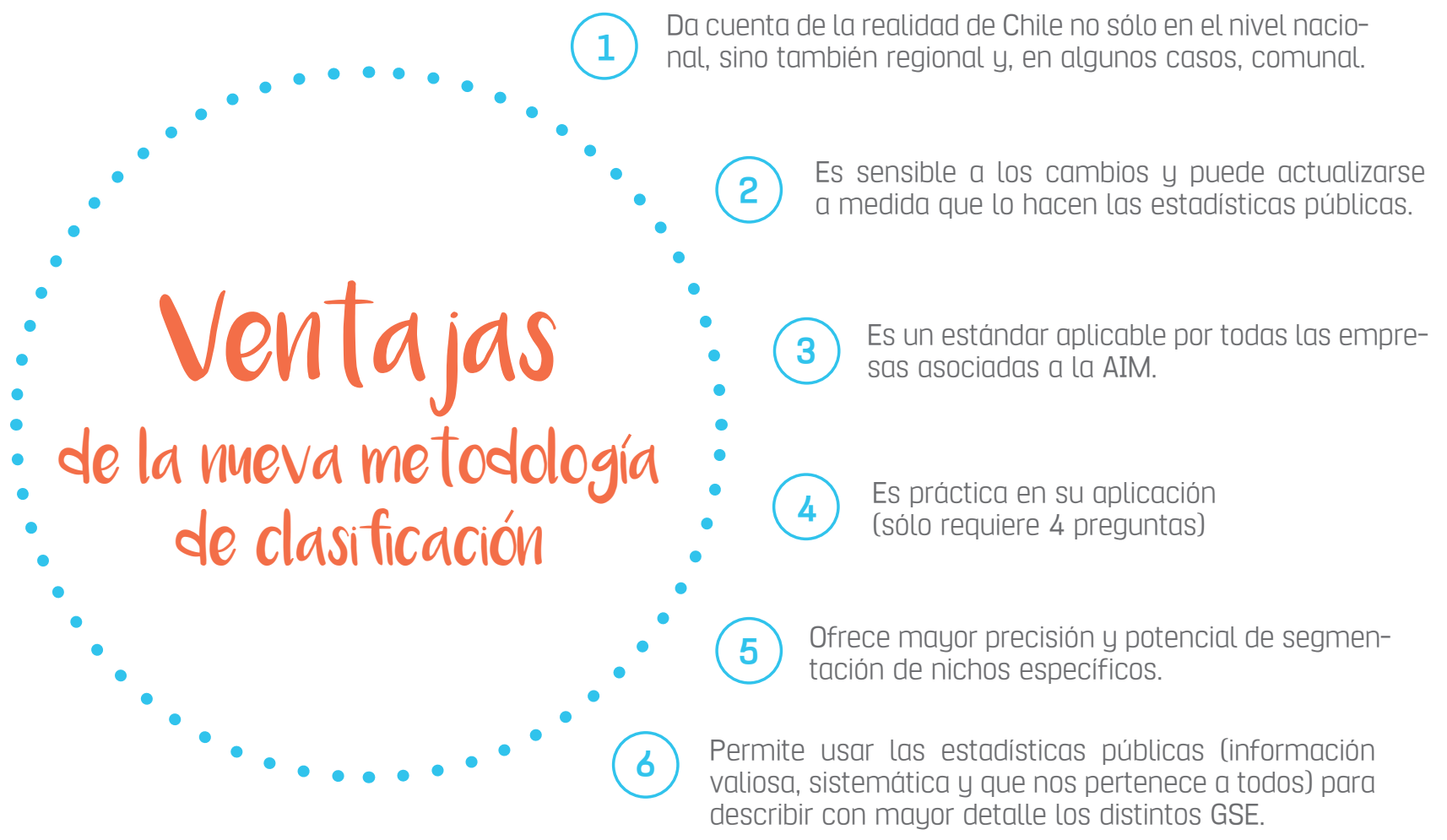




\section{Descripción de los GSE, segin las variables más discriminantes}

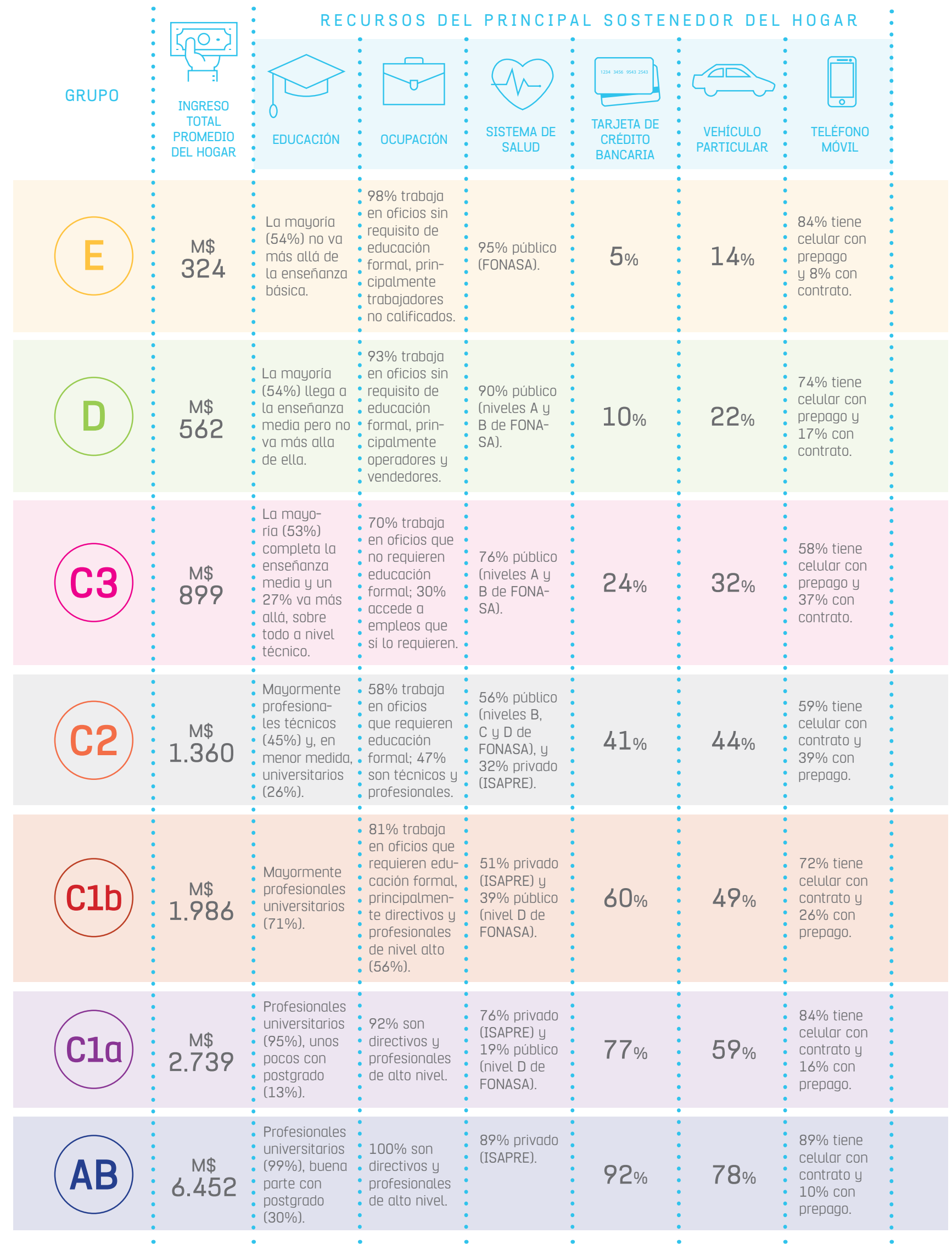




\section{Distribución de los Grupos Socioeconómicos}

(Proporción de hogares según encuesta CASEN, 2015).

$\%$ de hogares de cada GSE, NIVEL GRAN SANTIAGO.

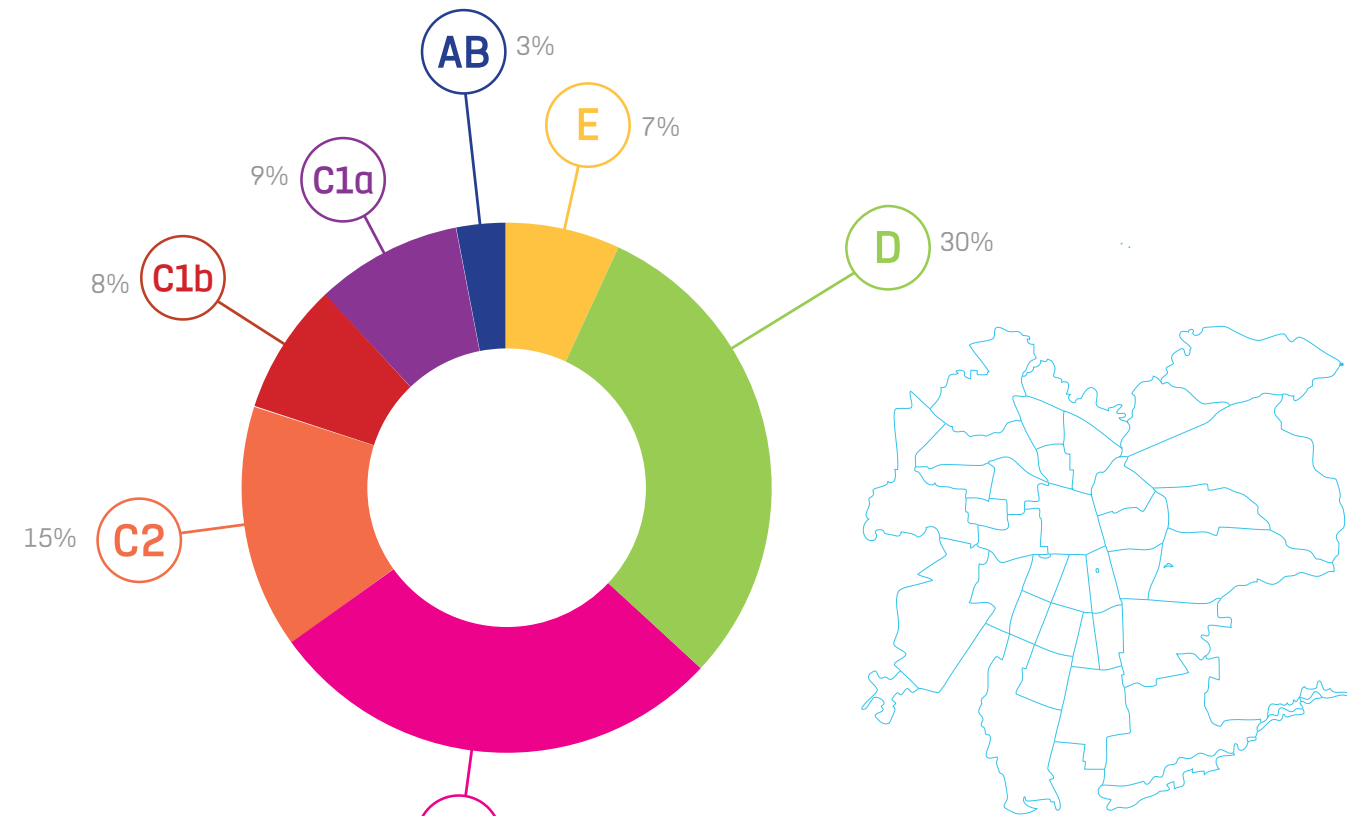

(C3) $28 \%$

\% de hogares de cada GSE, NIVEL PAÍS.

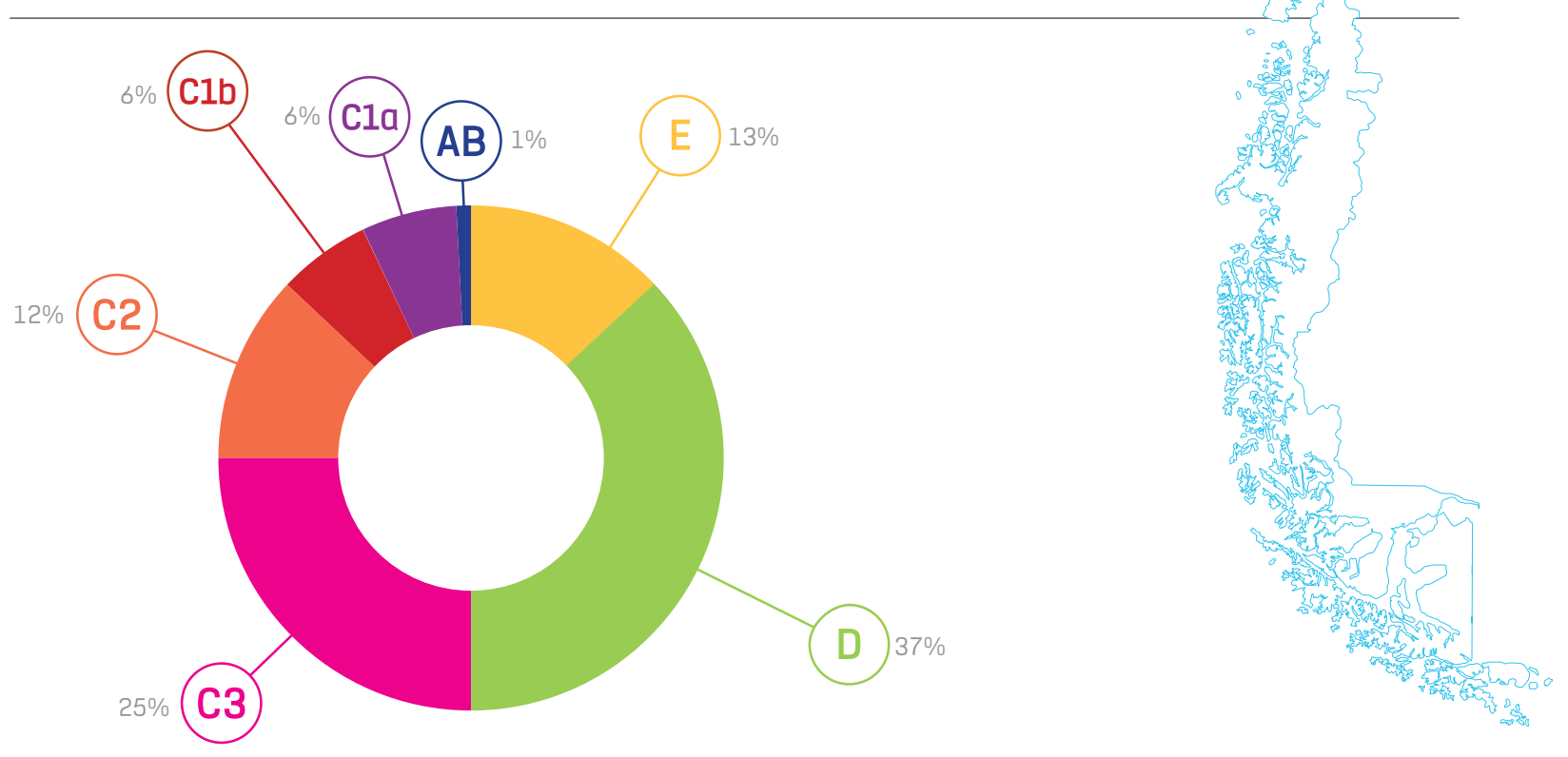


$\%$ de hogares de cada GSE, NIVEL REGIONES.

\begin{tabular}{|c|c|c|c|c|c|c|c|c|}
\hline REGIÓN & $E$ & $\mathrm{D}$ & C3 & $\mathrm{C2}$ & C1b & Cla & $A B$ & total \\
\hline Arica y Parinacota (XV) & 8,7 & 38,4 & 27,8 & 12 & 7 & 5,7 & 0,5 & 100 \\
\hline Tarapacá (I) & 7,8 & 32,2 & 30,4 & 12,4 & 7,8 & 7,5 & 1,9 & 100 \\
\hline Antofagasta (II) & 4,8 & 25,7 & 35,7 & 19 & 7,6 & 6,2 & 0,9 & 100 \\
\hline Atacama (III) & 7,5 & 35,1 & 35 & 12,3 & 6,3 & 3,3 & 0,6 & 100 \\
\hline Coquimbo (IV) & 15 & 42,2 & 24 & 9,5 & 4,7 & 4,3 & 0,2 & 100 \\
\hline Valparaiso (V) & 11,3 & 38,3 & 26,1 & 12,1 & 6,5 & 5 & 0,7 & 100 \\
\hline Metropolitana (XIII) & 7,9 & 31,3 & 27,3 & 14,1 & 7,9 & 8,8 & 2,8 & 100 \\
\hline O'Higgins (VI) & 17,7 & 41,4 & 24 & 8,6 & 4,2 & 3,8 & 0,2 & 100 \\
\hline Maule (VII) & 22 & 45,7 & 19 & 7,3 & 3,3 & 2,2 & 0,5 & 100 \\
\hline Biobio (VIII) & 18,5 & 42,9 & 21 & 8 & 5,4 & 3,7 & 0,5 & 100 \\
\hline Araucanía (IX) & 23,3 & 43,8 & 18,5 & 6,7 & 4,4 & 2,9 & 0,3 & 100 \\
\hline Los Ríos (XIV) & 18,4 & 39,1 & 22,4 & 9 & 5,4 & 5,2 & 0,6 & 100 \\
\hline Los Lagos (X) & 16,3 & 45,5 & 22,6 & 8,1 & 4,2 & 3,1 & 0,3 & 100 \\
\hline Aysén (XI) & 7,1 & 37 & 27,1 & 12,7 & 7,2 & 8 & 0,8 & 100 \\
\hline Magallanes y Antártica (XII) & 4,4 & 26,9 & 36,8 & 16,6 & 8,6 & 5,9 & 0,8 & 100 \\
\hline
\end{tabular}




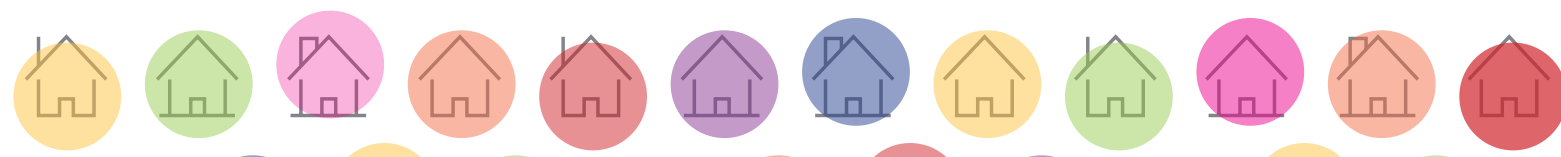

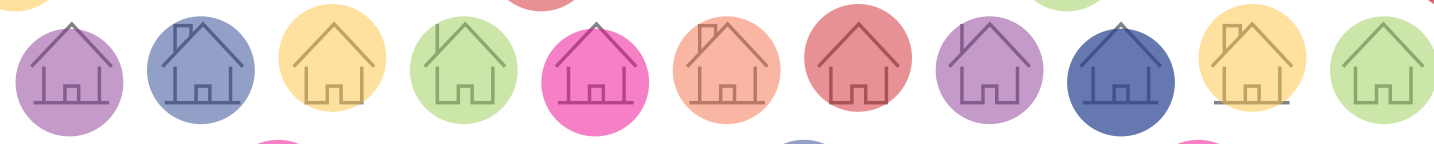

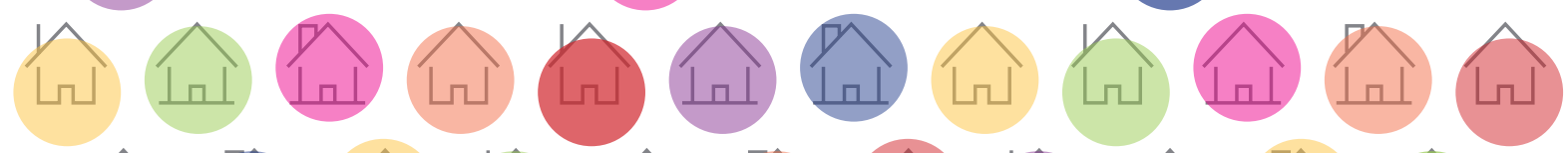

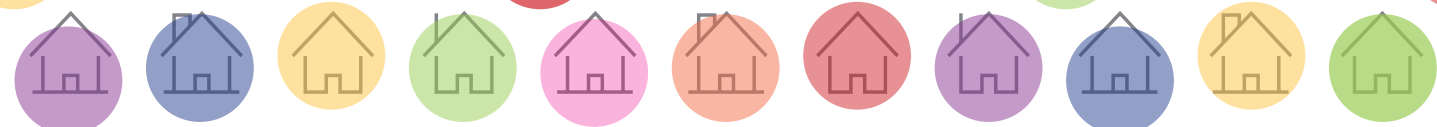

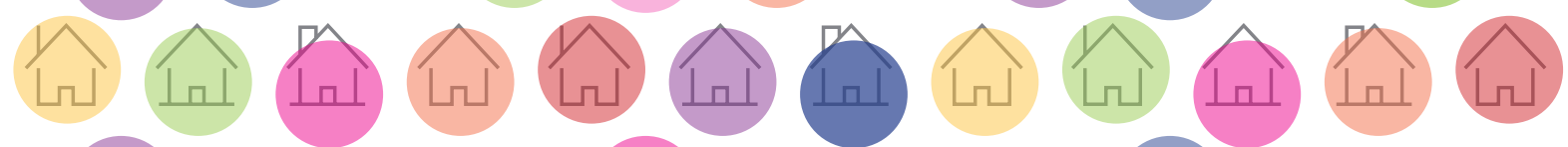

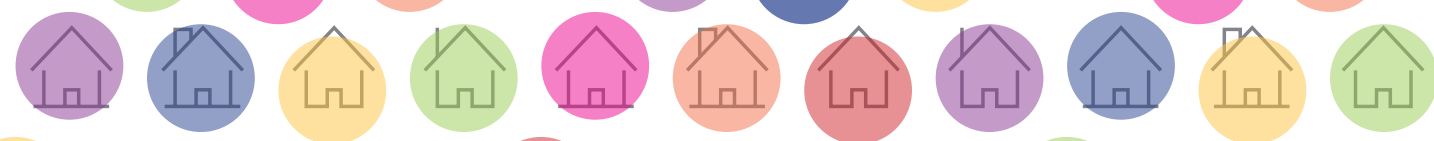

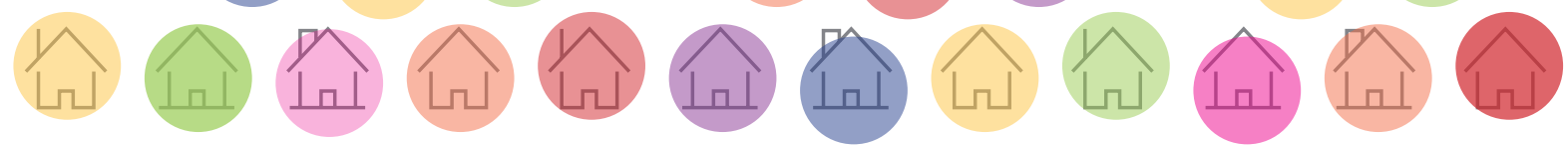

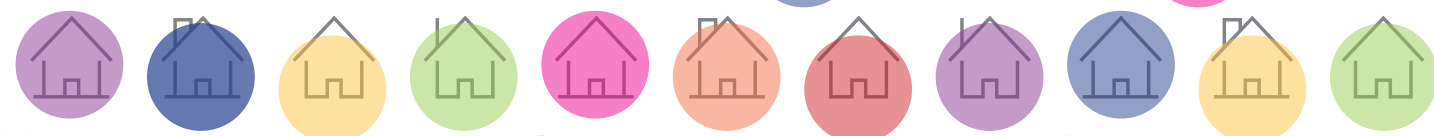
(iv) (1n) (n)

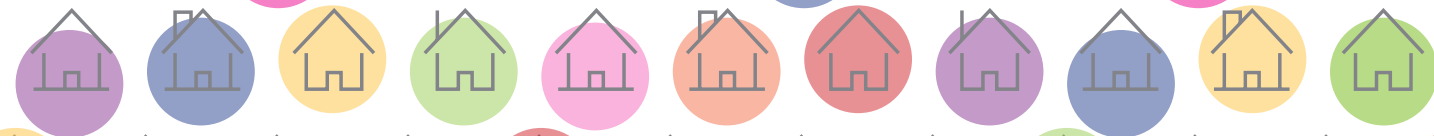

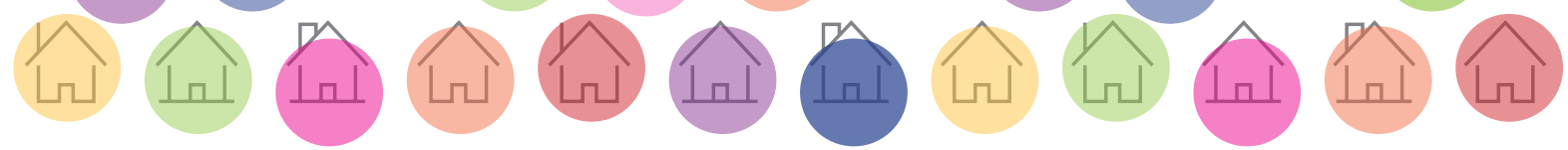

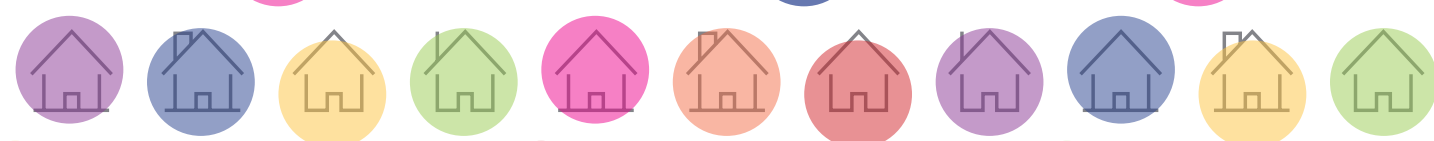

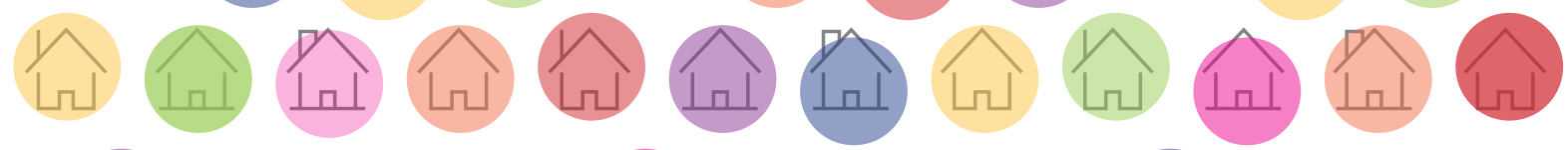

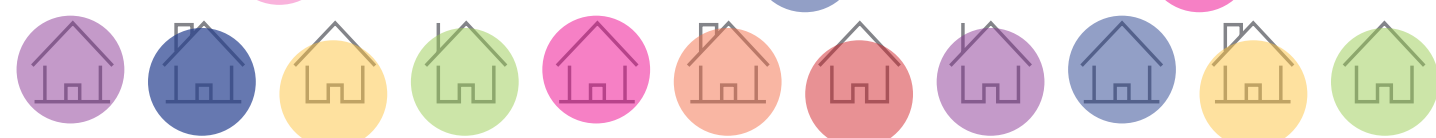
(iv) (II) (II)

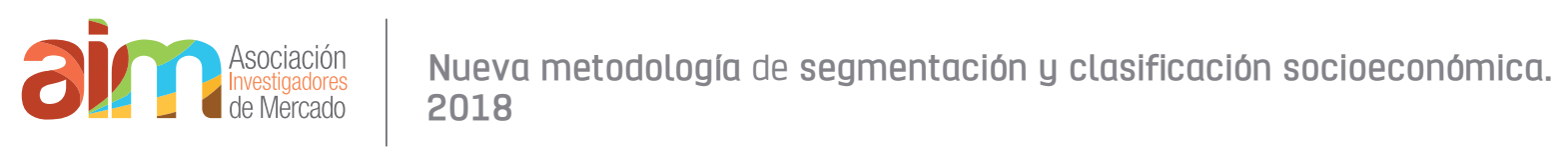

